\title{
MYALGIA OF THE NECK MUSCLES
}

\author{
Ernest M. Seydell, M. D. \\ Associate Editor \\ Archives of Otolaryngology
}

Gentlemen :

I consider it both a great honor and pleasure to have had this opportunity to meet the otoparyngologists and broncho-esophagologists of Japan, whose excellent scientific work has been recognized by all who are engaged in this speciality.

First let $\mathrm{m}:$ extend to the members of this organization the hearty greetings of the otolaryngologists and the broncho-esophagologists of the United States.

To further express to you the sentiment of the medical men of my country towards Japanese medicine, I was asked by the editor of the Journal of the American Medical Association to produre a correspondent for the Journal so that the medical events of Japan would appear in the Journal along with those of other nations.

Finally as associate editor of the Archives of Otolaryngology I would like you to know that the pages of the Archives are open to you for the publication of otolaryngological papers.

Next I wish to tell you that I had no idea when I left my home that I would have this opportunity to meet with you and much less that $I$ would be asked to speak to you on some medical subject. All of this came about through Dr. Hara. It was he that procured the films that you are to see and was kind enough to present me with a number of letters of introduction to members of your group.

Since you have so highly honored me in asking me to say a few words to you I have chosen for my subject MYALGIA OF THE NECK MUSCLES, often erroneously called Myositis.

My reason for choosing this subject is that throughout many years that I have practiced otolaryngology I have found that a large percentage of the patients that came to me complaining of headache had myalgia of the neck muscles. In fact in my experience it is the most common cause for headache in those patients that present themselves to the otolaryngologist with this complaint.

I first became acquainted with this symptom complex through Dr. Halle, in Berlin, in 1925. Since then this symptom complex has been of more than usual interest to me, possibly, because I happen to be one of its victims.

\section{SYMPTOMS}

Commonly the headaches begin in the morning, shortly after arising. The pain may be localized in the occiput or frontal region, or both. It may be unilateral or bilateral."

The scverity of the pain may range from a slight annoyance to pain so severe that an opiate may only offer slight relief.

The hradache may persist for only a short time or may continue without relief for weeks. When this occurs the patient often finds it difficult to remain in a prone 
position and feels most comfortable when upright holding his head in his hands.

When the pain is sever it may become generalized and may exterf into the superior maxilla and teeth. Pain in the ear is a very frequent symptom. In some cases there is no complaint of pain or soreness in the neck nuscles although a severe headache may be present. In others the pain is localized only in the neck muscles.

Myalgic headaches are often accompanied with mild vertigo, inability to concentrate, loss of appetite, and a feeling of depression.

\section{ETIOLOGY}

The underlying cause of this condition is a physical allergy. All of these patients are sensitive to cold, especially cold drafts; even though some are not aware of the facts. There are, of course, many conditions that predispose the sensitized individual to all attack. Tension has especially been stressed, as a factor; other conditions such as food allergy, infectious diseases and above all occupational conditions such as stenographers, drivers of motor vehicles, in fact any one who is obliged to hold his head in one position for long periods of time. A still more important factor is exposure to drafts, sleeing with a window openat night, going out of $d$ sors without a hat and exposure to air conditioning, etc.

\section{DIAGNOSIS}

The history of the onset, the location of the pain and the finding of spastic neck muscles or nodules in the neck muscles usually clinches the diagnosis. The muscle spasm is detected by palpating the neck muscles with the second, third and fourth fingers tips, rubbing across the deep neck muscles in the occipital region. The sternomastoid muscle is rarely involved. flinches:

When pressure is applied to the tense muscles pain is elicited and the patient

\section{DIFFERENTIAL DIAGNOSIS}

There are of course numerous causes for headache which must be ruled out before making a diagnosis of myalgic headache as there are patients who have spastic neck muscles without apparently suffering very ill effect from them; therefore the constitutional causes of headache must be eiiminated, as well as headache caused by sinus infection, the so called Histaminic headache, headache due to the sphenopalatine ganglion, occipital nerve neuralgia, which by the way is frequently associated with myalgia. Finally one must remember that more than one cause for the headache may exist.

\section{TREATMENT}

My method of treatment is as follows: The wooden applicators tepped with a small amount of cotton, are dipped in a solution of $4 \%$ cocaine to which some adrenalin has been added. These are placed in each nostril and directed towards the sphenopalatine ganglion and allowed to remain for five minutes. Then two fine light weight metal applicators are tepped with cotton and dipped in adrenalin solution, with these a small amount of flake cocaine is picked up and the applicators are placed in contact with the sphenopalatine ganglion on each side and allowed to remain there for ten minutes. It is well to warn the patient that he is to inform the nurse if any abnormal reaction occurs. After removal of the applicators there is considerable relaxation of the neck mus- 


\section{気食会報一3卷}

cles and also considerable relief from the head pain.

This procedure should be repeated a few times, usually not more than three applications are necessary. These may be repeated daily or every other day. In addition to the above treatment the author prescribes an ounce of $1 / 10000$ Histamine Diphosphate with the following directions: The mount should be dried by swallowing the contained saliva and then one drop of the solution is dropped under the tongue at about ten minutes before eating. The next day two drops before each meal are taken, then three, four, five six and seven. I have never found it necessary to use over seven drops three times daily. The drops are continued for one or two months.

Some patients are extremely sensitive to Histamine and in these individuals it may be necessary to start the treatment with a $1 / 100,000$ solution without developing a headache within 15-20 minutes after taking the drops. Under these circumstances the patient is told to take two drops less than the does that caused his headache and start the treatment form that point.

The patient must be told that he will accumulate a quantity of saliva during the ten minutes that the dorps are kept under the tongue; this is swallowed at the end of. the ten minutes period.

1023 First National Bank Bldg.

Wichita, Kansas, U.S. A.

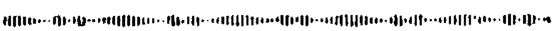

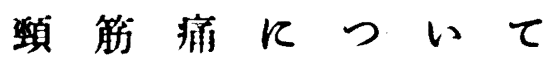

サイデル博士腾滋抄錄

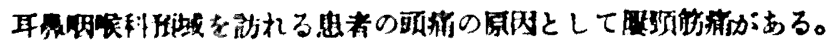

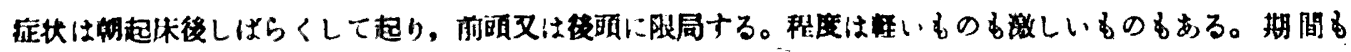

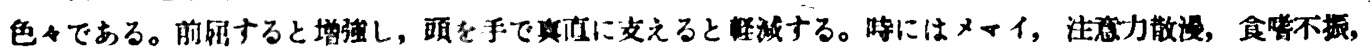

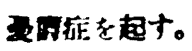

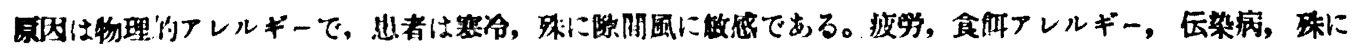

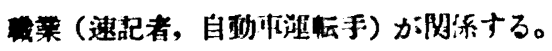

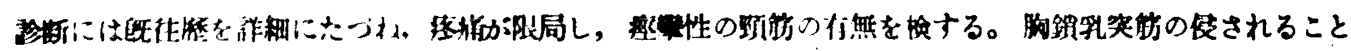
は少い。

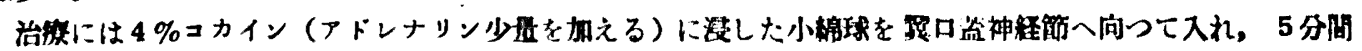

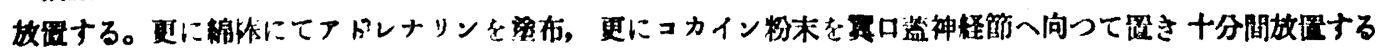
と嘼精は洋设ナる。

又, ヒスタミンの脱县作用法も用いられる。

（抄跀鯑木安 恒） 